\title{
Sexual selection and the evolution of preferential mating in ladybirds I. Selection for high and low lines of female preference
}

P. O'Donald and

M. E. N. Majerus
Department of Genetics, University of Cambridge, Downing Street, Cambridge CB2 2EH, England.

Fisher's theory of the evolution of female mating preference depends on the crucial premise that the preferences for specific male phenotypes are genetic. In natural populations of the Two-spot Ladybird, Adalia bipunctata, females prefer to mate with melanic males. We have created high and low lines of this preference: in the high line, we selected females that mated with melanic males; in the low line, we selected those that mated with non-melanic males. Two replicates of each line have been maintained. In the high line, the preference rose from 20 per cent of females preferring melanic males in the base population to 65 per cent after nine generations of selection. In the low line, the preference has been virtually eliminated.

The rapid response to selection shows that the female preference is highly heritable. Its heritability can be estimated from the response. We derive formulae for the estimation of the heritability and its variance according to two different genetic models of preference. In one model, a preferential mating tendency is assumed to be normally distributed and hence determined by many genes. In the other model, the preference is an all-or-nothing character such as might be determined by a single gene. All our experiments have shown a large initial response to selection. The normally distributed polygenic model gives heritabilities that are consistently too high when calculated from the initial response. The single gene model gives more realistic estimates.

As a sociobiological theory of the evolution of sexual behaviour and sexual differences, sexual selection now rests on a secure foundation: females do prefer some males to others; their preferences are genetic and evolve along with the preferred characters of the males.

\section{INTRODUCTION}

Darwin (1871) originally put forward the theory of sexual selection to explain the evolution of extreme or exaggerated differences between the sexes. Male competition explained the evolution of the much greater size of males in some species, particularly in those polygynous species in which the males compete for a harem of females. This would also explain the evolution of male weapons for fighting, such as spurs, horns and antlers. Darwin explained the development of male characters for sexual display by selection arising from female choice. This idea was controversial, for it was felt to imply conscious discrimination and choice by the females. Darwin denied this implication. He argued that a more striking male display would more readily excite the females. They would thus respond to and mate with the more striking males.
Recent experimental work has strongly corroborated Darwin's theory of sexual selection by female choice. Male Threespine Sticklebacks develop a red throat in the breeding season. Some stickleback populations are polymorphic with both red and non-red males present in the breeding season. Semler (1971) found that in aquaria females strongly preferred to lay their eggs in the nest of a red throated male when given the choice of nests of red and non-red males. It was the red throat that the females responded to, because nonred males painted with a red throat were just as successful as naturally red throated males.

An elegant experiment showed that females prefer male widow birds with longer tails. Andersson (1983) caught males on similar territories and cut off part of the tail feathers. Some of the cut feathers were glued onto birds with normal length tails to give birds with much longer tails. Others were left with normal, or shorter tails. 
All males were treated alike: their tails were all cut and reglued. The long-tailed males had the greatest reproductive success, mating more often and producing more offspring.

These experiments prove that female choice rather than any form of male competition gave rise to the variation in mating success between the males. Many experiments have been strongly suggestive of female choice although some competition between males may also have occurred and was not excluded by experimental design. The "rare male effect" so very often observed in experiments in which females are offered a choice between two different male genotypes or phenotypes will almost inevitably occur when females have specific mating preferences: rare males are preferred by a relatively greater proportion of females than common males; the selection is negatively frequency-dependent, becoming weaker as the preferred males become more common. This "rare male effect" has been observed very commonly in Drosophila (Ehrman, 1967; 1968; 1970; 1972; Spiess, 1968; Spiess and Spiess, 1969; Spiess and Ehrman, 1978), in a parasitic wasp Mormoniella vitripennis (Grant, Snyder and Glessner, 1974), in the guppy (Farr, 1977) and in the Two-spot Ladybird (Muggleton, 1979; O'Donald and Muggleton, 1979; Majerus, O'Donald and Weir, 1982a).

Although female choice has now been shown to operate in favour of specific male phenotypes, Darwin's theory had the weakness that it did not explain the origin or persistence of specific female preferences: the existence of female preference was a premise of the theory. If females were merely excited by male displays, they would choose any male with a sufficiently striking display. This behaviour would not produce any consistent line of development of the male display character. To give rise to further development of a male character, a specific and persistent preference would have to be maintained. Fisher (1930) solved this problem by giving an evolutionary explanation for the origin of female preference. He postulated that if females varied genetically in their abilities to discriminate between male phenotypes and their propensities to mate with them, preference for an advantageous male phenotype would be selected in association with the preferred character: females that mated preferentially with advantageous males would produce sons more likely to possess both the genes for the advantageous male character and the genes for the preference than sons of other matings. As the advantageous character is selected, so is the preference in association with it. As the preference increases among the females, the preferred males gain an increasing advantage; this in turn selects the preference genes, further increasing the preference. Fisher stated that the rate of this increase would be geometric. In genetical terms, the genes for the preference are selected in linkage disequilibrium with the genes for the preferred character. If the preference genes start at a very low frequency, the preferred males must start with some other selective advantage, additional to the very weak selection derived from the preference. But as the preference becomes more common, it may become the main selective force. The dynamics of the process of the joint selection of preferred character and preference are very complex (O'Donald, 1962; 1967; 1980; Lande, 1981; Kirkpatrick 1982), particularly when females have preferences for more than one male phenotype (O'Donald, 1980). Kirkpatrick has suggested that the initial preference might be the incidental effect of some other aspect of behaviour. An animal that feeds on red fruits, for example, may also be attracted by a patch of red on a possible mate. A red phenotype would thus start with some initial mating advantage which in turn would select genes for a specific mating preference, thus setting off the Fisher "runaway process".

Models of Fisher's theory have been formulated in genetical terms by O'Donald (1962; 1967; 1980), Lande (1981) and Kirkpatrick (1982). In O'Donald's models, a diploid organism has preferences determined by two or more alleles at one locus and preferred phenotypes determined by alleles at another locus. Generally, recessive alleles are selected more rapidly than dominants. The rate is geometric only at the start, slowing down rapidly later, contrary to Fisher's statement. Preferences for heterozygous phenotypes are eliminated, since the essential linkage disequilibrium cannot arise. In Lande's model, preference and preferred character are both polygenic: they are assumed to be normally distributed, and hence determined by an indefinitely large number of loci each with very small effects. This leads to an approximately constant association between preference and preferred character and hence to selection for preference proportional to selection for the preferred character. Since selection for the preferred character is produced by the preference, the preference is selected geometrically as Fisher stated. Both preference and preferred character continue to increase without limit. Of course, this is biologically unrealistic. It may be that only a small number of loci actually determine the females' preference. This would necessarily place genetic limits on the ulti- 
mate level to which preference or preferred character could be selected. Kirkpatrick's model is essentially a two locus model of preference and preferred character in haploids. Kirkpatrick obtained analytical results qualitatively similar to O'Donald's computer simulations of a single preference for a specific phenotype. Lande's models make the extreme assumption that infinitely many loci determine the preference and preferred character; O'Donald's and Kirkpatrick's at the other extreme assume that one locus determines preference, and another the preferred character. This latter assumption is of course true when the preferred character is the phenotype of a particular allele in a polymorphism-such as the quadrimaculata phenotype of the ladybird Adalia bipunctata. But assumptions as to the genetics of the preference can still be crucial to the outcome of selection. In O'Donald's diploid models, dominance has a strong effect on the rates of selection. The level of preference, how it is expressed and whether preferences exist for more than one phenotype are other important factors that influence the consequent selection (O'Donald, 1980), All the models agree on the main point, however: Fisher was right in suggesting that if a female preference is genetic, it will produce sexual selection for the preferred males that will also select the preference itself. Fisher's "runaway process" can certainly occur; its rate depends critically on the genetics of the characters.

\section{EXPERIMENTS ON SELECTION FOR} FEMALE PREFERENCE

Fisher's theory of sexual selection rests wholly on the premise that female mating preferences exist and are genetically determined in natural populations. Non-genetic preferences arising incidentally out of other learnt behaviour (e.g. imprinting on parental or sibling phenotypes) could never evolve further and would not give rise to a runaway process. A genetic analysis of the preference is essential to test which of Lande's or O'Donald's or Kirkpatrick's models are nearest the truth. But first it must be shown that mating preferences are indeed genetic.

So far, only one experiment has been carried out to test the genetic hypothesis of female preference. This was a selection experiment. Majerus, O'Donald and Weir (1982a) showed that both in natural populations in the field and in experimental populations in the laboratory, the melanic quadrimaculata males of the Two-spot Ladybird,
Adalia bipunctata have a mating advantage that fits a simple model of preferential mating. If this is produced by a genetically determined female preference, it should be possible to select for increased preferential mating in the population. By selecting females that had mated with melanic males, Majerus, O'Donald and Weir (1982b) raised the proportion of the preferential matings from 20 per cent to 56 per cent in the course of four generations. They proved that female preference had indeed been selected by the following experiment. Males from the original unselected stock of ladybirds were placed in a population cage with females from the selected line: the level of preference was similar to that in the fourth generation of the selected line- -54 per cent preferential matings. Males from the selected line were placed in a population cage with females from the original stock: about 20 per cent mated preferentially as in the original stock. Although female mating responses have not been studied, it is clear that some female character has been selected for increased response to melanic males: the female preference is genetic.

Unfortunately, our selected and control lines suffered a drastic loss of numbers and could not be maintained. The losses were caused in part by egg and larval cannibalism in periods of aphid scarcity, and in part because the numbers of typica non-melanic ladybirds segregating in the selected line had become very low. The experimental design requires the restoration of a $7: 3$ typ :quad ratio at the beginning of each generation; yet, as the preference for the dominant quadrimaculata males increases, fewer typica ladybirds are produced by genetic segregation.

Recently we have repeated and extended this selection experiment. We have used a much larger initial population and in certain generations built up population numbers by allowing a generation to pass without selection. The problem of "losing" typica has thus been avoided. Better aphid maintenance and the use of an artificial medium for adults has also greatly reduced egg and larval cannibalism. We have now selected within replicated lines for both high and low expression of preference. This paper describes the results of these experiments. The responses to selection have been used to estimate the heritabilities of preference according to two different genetic models. One model assumes that the preference is normally distributed and expressed at a certain threshold value. Implicitly, many loci are assumed to determine the tendency to preferential mating. The other model assumes that preference is a simple, discrete 
character such as might be determined by a single gene. These assumptions correspond to the assumptions of the two models of the evolution of preference: either Lande's polygenic model on the one hand; or, on the other, O'Donald's model of preference determined by dominant or recessive alleles.

\section{MATERIALS AND METHODS}

Adalia bipunctata is polymorphic for many melanic and non-melanic phenotypes. In our selection experiments we have used the commonest melanic, quadrimaculata (Q) and the non-melanic typica (T). The stock we used had been derived from very large samples taken on the campus of Keele University in Staffordshire, England.

In all mating tests, phenotypes have been tested at the ratio $3 \mathrm{Q}: 7 \mathrm{~T}$. This ratio gives efficient estimates of the mating preferences; it must be constant to eliminate any effect of frequency-dependent expression of preference. $\mathrm{Q}$ and $\mathrm{T}$ males at frequencies $v$ and $1-v$ are placed in a population cage with the females. Pairs are removed and the males are replaced after mating. The males' frequencies thus remain constant at the ratio $v \mathrm{Q}$ : $(1-v) \mathrm{T}$. If $\gamma$ of the females mate preferentially with $\mathrm{Q}$ males, then matings occur at the following frequencies:

$\begin{array}{lll} & \text { Matings of females } \\ & \text { With Q males } & \text { With T males } \\ \text { Expected proportion } & \gamma+v(1-\gamma) & (1-v)(1-\gamma) \\ \text { Observed numbers } & n_{\mathrm{Q}} & n_{\mathrm{T}}\end{array}$

In our experiments, the phenotypes of individuals in copuli are recorded during continuous observation of the cage. Mating pairs are removed and placed in petri-dishes. When the sexes have separated, the males are replaced in the cage. To select for increased preference within a High Line, females that had mated with Q males are allowed to lay their eggs in a new cage to produce the next selected generation in the High Line. To select for a Low Line of reduced preference, females that had mated with $T$ males lay the eggs of the next generation. We have maintained four selection lines: two replicated High Lines and two replicated Low Lines. In a particular generation, the preference is estimated by

$$
\hat{\gamma}=\frac{n_{\mathrm{Q}}(1-v)-n_{\mathrm{T}} v}{(1-v)\left(n_{\mathrm{Q}}+n_{\mathrm{T}}\right)}
$$

This is the maximum likelihood estimate with variance

$$
\operatorname{var}(\hat{\gamma})=\frac{(1-\gamma)(\gamma+v-\gamma v)}{(1-v)\left(n_{\mathrm{Q}}+n_{\mathrm{T}}\right)}
$$

In this model of expression of preference, a constant proportion $\gamma$ of the females always mate preferentially. More realistically, we should expect that expression of preference would depend at least to some extent on the frequency of the males preferred. Females are more likely to encounter a preferred male and hence to mate preferentially when preferred males are common than when they are rare. If females have not met a preferred male after a number of encounters with courting males, they will presumably give up the search and mate with the next male they meet. This idea is the basis of the "Encounter Models" of the expresson of preference (O'Donald, 1978a, b; 1980; Karlin and Raper, 1979; O'Donald and Majerus, 1984). General models of expression of preference have been formulated in terms of the females' "strength of preference" and the probabilities they encounter males they prefer (O'Donald and Majerus, 1984). These models give rise to expression of preference that is a function of male phenotypic frequency. In particular cases, this frequency-dependent function will be a complicated algebraic expression. But provided $v$ is a constant frequency of the preferred males, it can then be shown that $\gamma$ will always be the same constant fraction of the total proportion of the females with the preference. Thus, although $\gamma$ may not necessarily measure the total level of preference, it can be used to measure the relative magnitude of the preference over the successive generations of the selection experiments provided that the preferential mating is always tested at the same ratio of $\mathrm{Q}: \mathrm{T}$ males. In all our experiments, we used the frequency $v=0 \cdot 3$, i.e. the ratio $3 \mathrm{Q}: 7 \mathrm{~T}$ males. The total frequency of females with the preference may be somewhat larger than $\hat{\gamma}$, the estimated proportion mating preferentially. The constancy of $v$ ensures that the ratio of $\gamma$ to the total preference remains the same so that estimates of preference can be compared across the lines and generations in the experiment.

\section{RESULTS OF SELECTION FOR} FEMALE PREFERENCE

The data of the first selection experiment are shown in table 1. Majerus, O'Donald and Weir (1982b) analysed these data by comparing the differences between generations 1 and 4 in the selected (S) 
Table 1 First experiment of selection for preferential matings of male ladybirds in cages with phenotypes at constant ratio Q:T::3:7 (Majerus, O'Donald and Weir, 1982b)

\begin{tabular}{lllll}
\hline Generation & \multicolumn{2}{l}{$\begin{array}{l}\text { Numbers Mating } \\
\mathrm{Q}^{*}\end{array}$} & $\begin{array}{l}\text { Estimate of } \\
\text { Preference } \hat{\gamma} \pm \sqrt{\operatorname{var}(\hat{\gamma})}\end{array}$ \\
\hline S line & 1 & 52 & 70 & $0.180 \pm 0.064$ \\
& 2 & 31 & 23 & $0.392 \pm 0.096$ \\
& 3 & 28 & 16 & $0.456 \pm 0.107$ \\
& 4 & 39 & 17 & $0.566 \pm 0.088$ \\
C line & 1 & 28 & 29 & $0.273 \pm 0.095$ \\
& 2 & 18 & 19 & $0.266 \pm 0.117$ \\
& 3 & 28 & 28 & $0.286 \pm 0.096$ \\
& 4 & 33 & 41 & $0.209 \pm 0.083$ \\
\hline
\end{tabular}

$\mathrm{S}$ is the selected line, $\mathrm{C}$ the unselected, control line.

and control (C) lines. For this comparison, they obtained

$$
\chi_{1}^{2}=6 \cdot 27
$$

corresponding to

$$
P=0.0123
$$

showing a highly significant increase in the $\mathrm{S}$ line compared to the $\mathrm{C}$ line. This analysis ignored the data of generations 2 and 3 . We have now reanalysed the data using a regression model. This gives the analysis shown in table 2 . A more significant difference is then obtained than in the original analysis based only on generations 1 and 4: for the difference in the regressions in the $S$ and

Table 2 Analysis of $\chi^{2}$ of data of first experiment of selection for mating preference (table 1)

\begin{tabular}{|c|c|c|c|}
\hline Component of variation & $\begin{array}{l}\text { Value of } \\
x^{2}\end{array}$ & $d f$ & $\begin{array}{l}\text { Value of } \\
P\end{array}$ \\
\hline Regression on generations & $13 \cdot 1816$ & 1 & 0.00028 \\
\hline Residual & 0.5921 & 2 & 0.744 \\
\hline Total for $2 \times 4$ table & $13 \cdot 7737$ & 3 & 0.00323 \\
\hline
\end{tabular}

(i) The $S$ line

(ii) The C line

\begin{tabular}{llll} 
Component of variation & $\begin{array}{l}\text { Value of } \\
\chi^{2}\end{array}$ & $d f$ & $\begin{array}{l}\text { Value of } \\
P\end{array}$ \\
\hline Regression on generations & 0.2282 & 1 & 0.633 \\
Residual & 0.2357 & 2 & 0.889 \\
Total for $2 \times 4$ table & 0.4639 & 3 & 0.927 \\
For regression of effect of Q on generations: \\
$b_{c}=0.07549 \pm 0.15800$ \\
To test difference of regression coefficient $b_{s}$ and $b_{c}$, \\
$\qquad \begin{aligned} \chi_{1}^{2}=7.895 \\
P=0.00496\end{aligned}$ \\
\end{tabular}

C lines.

$$
\begin{aligned}
\chi_{1}^{2} & =7.895 \\
P & =0.00496
\end{aligned}
$$

Although we had obtained a highly significant response to selection in our first selection experiment, this by itself does not represent a formal and rigorous proof that we had selected a female preference. We might have partly selected for those melanic males that were the most active and quickest to mate. This is unlikely to occur and would produce only very weak selection if most melanics mate. But it is a possibility that should be excluded. To exclude it, we tested males and females from the selected line with males and females from the unselected line. Table 3 shows our results (Majerus, O'Donald and Weir, 1982b). When selected females choose males from the unselected Keele stock, the level of preference is characteristic of the selected line: when unselected females choose males from the selected line the level of preference is characteristic of the unselected stock. Thus we had selected some aspect of female mating response towards quadrimaculata males. The females' mating preference was genetic. At this point the numbers of ladybirds in our selected and control lines diminished rapidly, a consequence, as we now know, of the cannibalism among larvae and the difficulty of maintaining

\begin{tabular}{|c|c|c|c|c|c|}
\hline \multirow{3}{*}{ 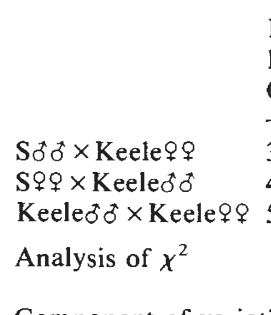 } & \multicolumn{2}{|c|}{$\begin{array}{l}\text { Numbers } \\
\text { Mating } \\
\text { Qむ To }\end{array}$} & \multicolumn{3}{|c|}{$\begin{array}{l}\text { Estimates of } \\
\text { Preference } \hat{\gamma} \pm \sqrt{\operatorname{var}(\hat{\gamma})}\end{array}$} \\
\hline & $\begin{array}{l}39 \\
44 \\
53\end{array}$ & $\begin{array}{l}51 \\
21 \\
63\end{array}$ & \multicolumn{3}{|c|}{$\begin{array}{l}0.191 \pm 0.075 \\
0.539 \pm 0.083 \\
0.224 \pm 0.066\end{array}$} \\
\hline & tion & \multicolumn{2}{|c|}{$\begin{array}{l}\text { Value of } \\
x^{2}\end{array}$} & $d f$ & $\begin{array}{l}\text { Value of } \\
P\end{array}$ \\
\hline $\begin{array}{l}\text { Selected males comp } \\
\text { with Keele males } \\
\text { Selected females com } \\
\text { with Keele females }\end{array}$ & $\begin{array}{l}\text { sared } \\
\text { mpare }\end{array}$ & $10 \cdot 4$ & & 1 & $\begin{array}{l}0.737 \\
0.00120\end{array}$ \\
\hline
\end{tabular}
typica.

Table 3 Proof that female preference has been selected, not male competitive ability

A second selection experiment was then started using ladybirds from a new sample of the wild Keele population collected in the following year (1983). Instead of a control line, Low Lines were set up, in which non-preferential matings with typica males were selected. Each selection line both 
high and low was replicated twice in order to maintain numbers and preserve genetic variability. The replicated lines were combined in generation 5 which was not then subject to selection for preferential or non-preferential mating. In the following selected generation 5, both high and low lines were again split up into two replicate lines. We used this procedure to reduce any inbreeding and keep up numbers of typica in the lines. In fact maintaining numbers presents fewer problems if the females' successive batches of eggs are laid in different petri-dishes, thus reducing larval competition for food and eliminating cannibalism.

The two replicates of the high and low lines are closely similar in all respects: they show no significant differences. They have therefore been combined to give the data shown in table 4 . In this table the unselected generation 5 has been omitted; the data given for generation 5 are those of the selected generation. Table 5 shows the analyses of $\chi^{2}$ for the high and low lines and the test of the difference in the regressions of the effect of $Q$ on generations.

The second selection experiment dramatically confirms the results of the first. Over nine generations in the high line, the level of preference has

Table 4 Matings of males in combined replicated experiments to select for and against preference for $Q$

(i) Selection for increased preference

High Lines (A and B Combined)

\begin{tabular}{|c|c|c|}
\hline$G$ & Qð̊: Tơ & $\hat{\gamma} \pm \sqrt{\operatorname{var}(\hat{\gamma})}$ \\
\hline 1 & $76: 98$ & $0 \cdot 195 \pm 0.054$ \\
\hline 2 & $47: 39$ & $0.352 \pm 0.077$ \\
\hline 3 & $67: 53$ & $0.369 \pm 0.065$ \\
\hline 4 & $73: 48$ & $0.433+0.064$ \\
\hline 5 & $132: 94$ & $0.406 \pm 0.047$ \\
\hline 6 & $129: 87$ & $0.425 \pm 0.048$ \\
\hline 7 & $117: 63$ & $0.500 \pm 0.051$ \\
\hline 8 & $125: 48$ & $0.604 \pm 0.049$ \\
\hline 9 & $125: 41$ & $0.647 \pm 0.048$ \\
\hline
\end{tabular}

(ii) Selection for reduced preference

Low Lines (A and B Combined)

\begin{tabular}{|c|c|c|}
\hline G & Qठี: Tठ & $\hat{\gamma} \pm \sqrt{\operatorname{var}(\hat{\gamma})}$ \\
\hline 1 & $76: 98$ & $0.195 \pm 0.054$ \\
\hline 2 & $32: 55$ & $0.097 \pm 0.074$ \\
\hline 3 & $43: 75$ & $0.092 \pm 0.063$ \\
\hline 4 & $41: 73$ & $0.085+0.064$ \\
\hline 5 & $62: 124$ & $0.048 \pm 0.049$ \\
\hline 6 & $57: 129$ & $0.009 \pm 0.048$ \\
\hline 7 & $69: 139$ & $0.045 \pm 0.047$ \\
\hline 8 & $46: 117$ & $-0.025 \pm 0.050$ \\
\hline 9 & $78: 130$ & $0 \cdot 107 \pm 0 \cdot 040$ \\
\hline
\end{tabular}

The lines $\mathrm{A}$ and $\mathrm{B}$ are the two replicates of the high and low lines
Table 5 Analysis of $\chi^{2}$ of data of second experiment of selection for high and low mating preferences

(i) The High Lines

\begin{tabular}{|c|c|c|c|}
\hline Component of variation & $\begin{array}{l}\text { Value of } \\
x^{2}\end{array}$ & $d f$ & $\begin{array}{l}\text { Value of } \\
P\end{array}$ \\
\hline Regression on generations & $45 \cdot 5628$ & 1 & - \\
\hline Residual & $4 \cdot 6604$ & 7 & 0.701 \\
\hline Total for $2 \times 9$ table & $50 \cdot 2232$ & 8 & $3.64 \times 10^{-8}$ \\
\hline \multicolumn{4}{|c|}{$\begin{array}{l}\text { For regression of effect of Q on generations: } \\
\qquad b_{\mathrm{H}}=0.9064 \pm 0.1343\end{array}$} \\
\hline
\end{tabular}

(ii) The Low Lines

\begin{tabular}{|c|c|c|c|}
\hline Component of variation & $\begin{array}{l}\text { Value of } \\
x^{2}\end{array}$ & $d f$ & $\begin{array}{l}\text { Value of } \\
P\end{array}$ \\
\hline Regression on generations & $4 \cdot 2680$ & 1 & 0.0388 \\
\hline Residual & $7 \cdot 7240$ & 7 & $0 \cdot 358$ \\
\hline Total for $2 \times 9$ table & $11 \cdot 9920$ & 8 & $0 \cdot 152$ \\
\hline \multicolumn{4}{|c|}{$\begin{array}{l}\text { For regression of effect of } \mathrm{Q} \text { on generations: } \\
\qquad b_{\mathrm{L}}=-0 \cdot 2957 \pm 0 \cdot 1431 \\
\text { To test difference of regression coefficients } b_{\mathrm{H}} \text { and } b_{\mathrm{L}} \\
\qquad \chi^{2}=38 \cdot 7509\end{array}$} \\
\hline
\end{tabular}

been raised from about 20 per cent of females expressing a preference to 65 per cent. In the low line, the preference has almost been eliminated: preference for $\mathrm{Q}$ males remains, however, at a low level of expression. This result in the low line suggests there may be no genetic variation in preference for $\mathrm{T}$ males: preference for $\mathrm{Q}$ may perhaps be eliminated eventually; but no genetic preference for $T$ is present to be selected. An earlier experiment also lead to this conclusion. Majerus, O'Donald and Weir (1982a) tested the matings of $\mathrm{Q}$ and $\mathrm{T}$ males over the range of frequencies 3Q:7T, 5Q:5T and 7Q:3T. If some females preferred $Q$ males and others $T$ males, this experiment over a range of male frequencies gives data by which both preferences can be estimated. Fitting a model with both assorting and non-assorting preferences for Q and T males, Majerus et al. found that the non-assorting preference for $\mathrm{Q}$ males was highly significant with M.L. estimate

$$
\hat{\gamma}=0 \cdot 231
$$

They also obtained the estimate

$$
\hat{c}=0 \cdot 160
$$

for an assorting preference for Q, which was not quite significant. Estimates of assorting and nonassorting preferences for $\mathrm{T}$ were almost zero. In this ladybird population, there exists a highly heritable female preference for Q males, but no preference for $\mathrm{T}$ males. 


\section{HERITABILITY OF THE FEMALE PREFERENCE}

From the selection differential applied to the parents and the response to selection in their offspring, a "realised" heritability

$$
h^{2}=2 \mathrm{R} / \mathrm{S}
$$

may be calculated for the population under selection. $\mathrm{S}$ is the selection differential measured by the deviation of the selected parents from the general population mean; $R$ is the response measured by the corresponding deviation of the offspring. Theoretically the realised heritability should equal the regression of offspring mean on mid-parental mean giving the estimate

$$
h^{2}=\mathrm{V}_{\mathrm{A}} / \mathrm{V}_{\mathrm{P}}
$$

where $V_{A}$ is the additive genetic variance and $V_{P}$ the total phenotypic variance.

To calculate the heritability of the females' preference for $Q$ from the results of our selection experiment, we must use a model of the expression of preference, for preference is not a measurable characteristic of an individual female, but a characteristic of a group or population of females and estimated according to a specific model of how the preference is expressed. We used a simple model with constant expression of preference in each generation. But, as we have already explained, even if the expression of preference were frequency-dependent, our estimates would still be comparable across different generations provided that constant ratios of $\mathrm{Q}$ and $\mathrm{T}$ males are used for testing. In the model of constant preference, the parameter $\gamma$ is the proportion of females that mate with $\mathrm{Q}$ males in excess of the proportion of random matings with $Q$ males: it is the proportion that actually exercised their preference for $Q$. In a simple polygenic model of the determination of preference, this would be the proportion above some threshold in level of preference. Suppose the females show continuous variation in their tendency to mate preferentially. If many loci determine the preferences, the distribution of preferential tendency will approximate to the normal. Suppose that above some point or threshold along the scale of preferential tendency, females mate preferentially; below it, they mate at random. Expression of preference would then be a threshold character.

Falconer $(1965 ; 1967)$ gave a method of estimating the heritability of threshold characters of the sort we have postulated for female preference. He used his method to calculate the heritability of the liability to certain human diseases: individuals vary in their liability to a disease; above some threshold, they are said to have the disease. The proportion with the disease is, of course, directly observed; whereas the proportion of females expressing a preference can only be estimated according to some model of the expression of preference. Nevertheless, Falconer's method can be modified for the estimation of the realised heritabilities of mating preferences.

Falconer's model Fig. 1 shows a standardised, normally distributed, preferential tendency. Above some threshold $\mathrm{x}$, along the scale of preferential tendency, females mate preferentially. The proportion of females that do so is the proportion $\gamma$, estimated from the mating choice experiments. These females have mean $i$; those that mate at random have mean $j$. We can then calculate the mean of the females in the high line that mated

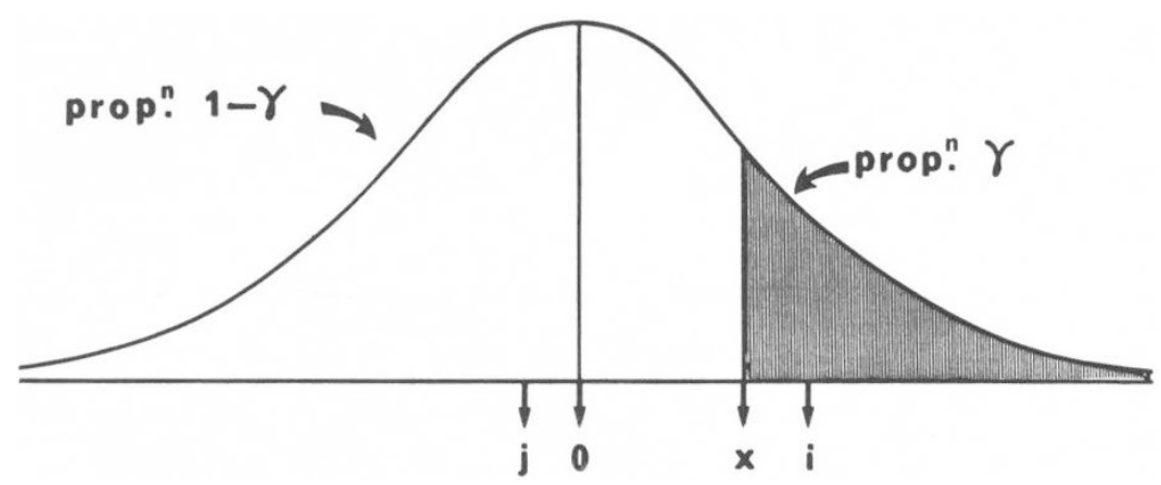

Figure 1 Threshold model of expression of female preference. Females are assumed to have a Normally distributed tendency towards preferential mating. At or above some threshold value $x$ in the distribution, females mate preferentially. These females, representing a proportion $\gamma$ of all females, have mean preferential tendency $i$. The remaining $1-\gamma$ females that mate at random have mean preferential tendency $j$. 
with the Q males:

Females' matings in the High Line

$$
\text { With Q males }
$$

With T males

$\begin{array}{lll}\text { Frequency } & \gamma+v(1-\gamma) & (1-v)(1-\gamma) \\ \text { Mean value } & \frac{\gamma i+j v(1-\gamma)}{\gamma+v(1-\gamma)} & j\end{array}$

Since the distribution has a mean of zero, we must have

$$
\gamma i+j v(1-\gamma)+j(1-v)(1-\gamma)=0
$$

so that

$$
j=-\gamma i /(1-\gamma)
$$

Hence the selection differential, which is the mean of the females who mated with Q males (being the deviation of the mean of the selected females from the population mean of zero), is given by

$$
S=\gamma i(1-v) /[\gamma+v(1-\gamma)]
$$

Then, if the proportion of females expressing a preference in the next generation is $\gamma^{\prime}$, corresponding to threshold $x^{\prime}$, we have, for the high line,

$$
\begin{aligned}
h^{2} & =2 \mathrm{R} / \mathrm{S} \\
& =2\left(x-x^{\prime}\right) / \mathrm{S}
\end{aligned}
$$

The values of $x$ corresponding to $\gamma$, and $x^{\prime}$ corresponding to $\gamma^{\prime}$, can be obtained from Falconer's table (Falconer, 1965); or, these days, as the inverse of the normal probability integral, at the push of a button on an electronic calculator or computer. The mean $i$, of the individuals with values greater than $x$, is given by,

$$
i=z / \gamma
$$

where $z$ is the height of the standard normal distribution at $x$. Falconer's table also gives values of $i$ corresponding to $\gamma$.

In the low line,

$$
\mathrm{S}=j
$$

and hence $h^{2}$ as for the high line.

Bulmer's model We owe to Dr Michael G. Bulmer an alternative model for the estimation of realised heritabilities. He suggested that mating preference could be regarded as a simple discrete character, such that

$X=1$ for "choosy" females mating preferentially $X=0$ for "non-choosy" females mating randomly.
Then, in the high line,

$$
\begin{aligned}
\gamma & =\operatorname{Prob}(X=1) \\
& =\mathrm{E}(X)
\end{aligned}
$$

$\mathrm{E}\{X \mid+q$ mating with $\mathrm{Q} ð ð\}=\gamma /[\gamma+v(1-\gamma)]$

$$
\begin{aligned}
\mathrm{S} & =\gamma /[\gamma+v(1-\gamma)]-\gamma \\
& =\gamma(1-\gamma)(1-v) /[\gamma+v(1-\gamma)]
\end{aligned}
$$

Since $\gamma^{\prime}$ are choosy in the next generation,

$$
\mathrm{R}=\gamma^{\prime}-\gamma
$$

and therefore

$$
\begin{aligned}
h^{2} & =2 R / S \\
& =\frac{2\left(\gamma^{\prime}-\gamma\right)(\gamma+v-\gamma v)}{\gamma(1-\gamma)(1-v)}
\end{aligned}
$$

In Bulmer's model, choosiness is a discrete variable, such as a phenotype determined by an allele of a single gene. If choosiness were wholly genetic and determined by a dominant allele, then it is easy to show that

$$
h^{2}=\frac{2 \sqrt{1-\gamma}}{1+\sqrt{1-\gamma}}
$$

while if it were determined by a recessive,

$$
h^{2}=\frac{2 \sqrt{\gamma}}{1+\sqrt{\gamma}}
$$

These values would represent the maximum attainable heritabilities in the single gene models.

The variances of the estimates of heritabilities are complicated functions of the parameters and the sampling variance of the proportion of matings with melanic males. Since the true values of the parameters are unknown, their estimates must be used as an approximation, which may be poor in small samples. The formulae for calculating the variances are derived in the appendix to this paper.

Table 6 gives the estimates of heritabilities with standard errors. The standard errors are of the same order of magnitude as the estimate of heritability obtained from the response to selection from one generation to the next. From the change of preference over only two successive generations, no significant estimate of heritability is thus obtained. This was to be expected, since, over only two generations, the changes of preference are not significant: though, as a trend over all generations, the change is highly significant $\left(\chi_{1}^{2}=45.56\right.$ in the high line).

In the low line, the effect of sampling variation is to produce absurdly high variation in the esti- 
Table 6 Esimates of heritabilities, A and B replicates combined

(i) High Lines

Heritabilities

\begin{tabular}{|c|c|c|}
\hline Generations & Bulmer's Model & Falconer's Model \\
\hline 1,2 & $1 \cdot 244 \pm 0 \cdot 840$ & $2 \cdot 165 \pm 1 \cdot 348$ \\
\hline 2,3 & $0.116 \pm 0.687$ & $0 \cdot 190 \pm 1 \cdot 127$ \\
\hline 3,4 & $0.440 \pm 0.619$ & $0.703 \pm 0.986$ \\
\hline 4,5 & $-0.193 \pm 0.560$ & $-0.308 \pm 0.895$ \\
\hline 5,6 & $0.130 \pm 0.461$ & $0.207 \pm 0.734$ \\
\hline 6,7 & $0.527 \pm 0.477$ & $0.826 \pm 0.749$ \\
\hline 7,8 & $0.770 \pm 0.493$ & $1 \cdot 221 \pm 0 \cdot 781$ \\
\hline 8,9 & $0.376 \pm 0.565$ & $0.615 \pm 0.917$ \\
\hline \multirow{3}{*}{$\begin{array}{l}\text { Mean } \\
\text { heritabilities } \\
\text { Heterogeneity in } \\
\text { heritabilities }\end{array}$} & & \\
\hline & $0.382 \pm 0.197$ & $0.622 \pm 0.315$ \\
\hline & $\chi_{7}^{2}=3 \cdot 278$ & $\chi_{7}^{2}=3 \cdot 526$ \\
\hline
\end{tabular}

(ii) Low Lines

\begin{tabular}{|c|c|c|}
\hline Generations & $\begin{array}{l}\text { Heritabilities } \\
\text { Bulmer's Model }\end{array}$ & Falconer's Model \\
\hline 1,2 & $0.316 \pm 0.278$ & $2 \cdot 575 \pm 2 \cdot 567$ \\
\hline 2,3 & $0.019 \pm 0.368$ & $0.305 \pm 5.932$ \\
\hline 3,4 & $0.026 \pm 0.344$ & $0.466 \pm 6.013$ \\
\hline 4,5 & $0.146 \pm 0.301$ & $3 \cdot 495 \pm 6 \cdot 406$ \\
\hline 5,6 & $0.161 \pm 0.278$ & $13 \cdot 229 \pm 37 \cdot 486$ \\
\hline 6,7 & $-0.165 \pm 0.320$ & $-53 \cdot 145 \pm 404 \cdot 183$ \\
\hline 7,8 & $0 \cdot 299 \pm 0.271$ & $5 \cdot 230 \pm 17 \cdot 825$ \\
\hline 8,9 & $-0.658 \pm 0.408$ & $-24 \cdot 637 \pm 72 \cdot 166$ \\
\hline \multicolumn{3}{|l|}{ Mean } \\
\hline heritabilities & $0.081 \pm 0.110$ & $1.982 \pm 1.962$ \\
\hline $\begin{array}{l}\text { Heterogeneity in } \\
\text { heritabilities }\end{array}$ & $\chi_{7}^{2}=5 \cdot 408$ & $\chi_{7}^{2}=0.542$ \\
\hline
\end{tabular}

Negative values of heritability occur when responses to selection are negative. These negative responses are merely the consequence of random sampling. With a small selection differential at low levels of preference, relatively large negative responses can occur by sampling error, giving absurd heritabilities.

mates of het itability from Falconer's model. It is easy to see why Falconer's model should lead to this absurdity. In the low line, very few, or no, preferential matings occur after generation 4: the preferential matings in Falconer's model would represent a small tail in the normal distribution of the preferential mating tendency of the females. All the remaining matings will be random. Hence, all those females below the threshold-the selected group of females that mated with $\mathrm{T}$ males-will have a mean very close to that of the whole population, so the selection differential will be very small. Large responses to selection should be impossible in this model since only a small tail of the distribution is not included in the selected group. Thus, if a large response does occur, it implies an impossibly high heritability in Falconer's model. Bulmer's single gene model does at least give reasonable estimates of heritability and is thus to be preferred on these grounds.

\section{CONCLUSIONS}

Our experiments prove that female two-spot ladybirds have a genetic preference to mate with melanic, quadrimaculata males. Their mating preference is highly heritable and responds rapidly to selection. We started with a sample from a wild population in which about 20 per cent of females mate preferentially with melanics. Nine generations of selection have been sufficient to produce a "High Line" in which about 65 per cent now mate preferentially with melanics. Females that mated with non-melanic, typica males have also been selected to produce a "Low Line". In the Low Line, preferential mating rapidly declined and mating is now virtually at random. So far, no preferential mating with typica males has evolved in the Low Line: apparently, a genetic preference exists only for melanics, not for typica.

The responses to selection have been used to calculate the realised heritability of the mating preference according to two genetic models. In one model, an underlying "preferential mating tendency" is normally distributed; above a certain threshold in the distribution, females mate preferentially. This model is a development of Falconer's model for estimating the heritability of liability to disease (Falconer, 1965). In another model, which Dr M. G. Bulmer suggested to us, expression of preference is regarded as an all-or-nothing variable: $X=1$ if females mate preferentially; $X=0$ if they mate randomly. Bulmer's model would thus correspond to the genetic determination of preference by a single gene; Falconer's to genetic determination by very many genes each with very small effects. As shown in the Appendix to this paper, we have derived heritabilty estimates and their variances for both these models. Bulmer's model gives the more reasonable estimates of heritability, with an average value of about 0.4 in the high line. Bulmer's model also fits the rapid change in preference in the first generation of selection. This has occurred in all of our selection experiments and is incompatible with realistic values of heritability in Falconer's model (see table 7 in which all our results on this point have been collected together). We have now set up isofemale lines from the tenth generation of the high line in order to analyse the genetics of preference. We shall thus test whether one, or a few, or many genes determine the female 
Table 7 Response to selection and heritability of female preference after one initial generation of selection

(i) Additional experiment of selection for one generation

Numbers of matings Estimates of

Generation $Q \times Q Q \times T T \times Q T \times T$ preference,

\begin{tabular}{llllll}
\hline$G 1$ & 28 & 39 & 31 & 59 & $0 \cdot 181 \pm 0.056$ \\
$G 2$ & 15 & 35 & 12 & 35 & $0.308 \pm 0.072$
\end{tabular}

This experiment was carried out to provide additional data of the initial response to selection for female preference. The ladybirds were taken from the same population at Keele as those used in the other selection experiments (tables 1 and 4 of this paper).

(ii) Heritabilities estimated by responses to selection after the initial generation

Estimates of heritabilities

Experiment Bulmer's Model Falconer's Model

\begin{tabular}{lcc}
\hline $\begin{array}{l}\text { 1st expt. (data } \\
\text { from table 1) }\end{array}$ & $1 \cdot 740 \pm 1 \cdot 144$ & $2 \cdot 962 \pm 1 \cdot 745$ \\
$\begin{array}{l}\text { 2nd expt. (data } \\
\text { from table 4) }\end{array}$ & $1 \cdot 244 \pm 0.840$ & $2 \cdot 165 \pm 1.348$ \\
$\begin{array}{l}\text { Additional expt. } \\
\text { (data above) }\end{array}$ & $1 \cdot 042 \pm 0.860$ & $1.896 \pm 1.448$ \\
$\begin{array}{l}\text { Combined data } \\
\text { of all expts. }\end{array}$ & $1 \cdot 270 \pm 0.531$ & $2 \cdot 235 \pm 0.857$ \\
\hline
\end{tabular}

preference and hope to find markers linked to the preference genes. If there is one single major preference gene, this would accord exactly with the basic premise of O'Donald's models of the evolution of mating preference (O'Donald, 1967; 1980). The rate and ultimate outcome of this evolutionary process is critically dependent on the dominance relations of the preference alleles. Knowledge of the genetics of preference and preferred phenotypes will permit us to formulate a detailed genetic model of ladybird evolution and thus to make specific predictions for further testing.

In the more general context of the evolution of social behaviour, we believe that our experiments provide the first, formal and, indeed, complete proof that a female mating strategy is genetically determined. Females do make alternative, genetically determined choices between the males. We have certainly refuted an objection, often raised against sociobiological theories, that the postulated behavioural adaptations have never been shown to be genetically determined. Sociobiologists assert that different strategies of animal behaviour-the different, alternative courses of action that an animal might take-are inherited and thus can evolve by natural or sexual selection: strategies, for example, such as whether to be a "hawk" or "dove" in conflicts, or whether to choose one type of male as a better mate than others. Of course, many aspects of behaviour must vary in some degree genetically and thus produce variation in the chances of success in conflicts or in finding mates. But does an animal prefer to follow one course of action rather than another, and is its preference hereditary? As dogmatically as some sociobiologists have answered "Yes", so have environmentalists answered "No". On this issue of the so-called "sociobiological debate", the arguments have been political and ideological rather than scientific. Extreme views can persist in the absence of any experimental evidence. On the crucial premise of the genetic determination of social behaviour and behavioural strategies, sociobiology has remained largely theoretical. Now at least, the theory of sexual selection, rests on a wholly secure foundation of biological fact: females do prefer some males to others; their preferences are genetic; preferred males do gain a sexual selective advantage.

Acknowledgements We most gratefully acknowledge a grant from the Wolfson Foundation to build a new laboratory in which our work has been carried out. An SERC Research Grant provides essential support for our research. Mr P. W. E. Kearns and $\mathrm{Miss} \mathrm{H}$. Ireland gave most valuable technical assistance with our experiments.

\section{REFERENCES}

ANDERSSON, M. 1982. Female choice selects for extreme tail length in a widow bird. Nature, 299, 818-820.

DARWIN, C. R. 1871. The Descent of Man and Selection in Relation to Sex. John Murray, London. 
EHRMAN, L. 1967. Further studies on genotype frequency and mating success in Drosophila. Amer. Natur., 101, 415-424.

EHRMAN, L. 1968. Frequency-dependence of mating success in Drosophila pseudoobscura. Genet. Res., Camb., 11, 135140.

EHRMAN, L. 1970. The mating advantage of rare males in Drosophila. Proc. Nat. Acad. Sci., U.S.A., 65, 345-348.

EHRMAN, L, 1972. Genetics and sexual selection. In Sexual Selection and the Descent of Man 1871-1971, B. Campbell (ed.), pp. 105-135. Heinemann, London.

FALCONER, D. S. 1965. The inheritance of liability to certain diseases, estimated from the incidence among relatives. Ann. Hum. Genet, Lond., 29, 51-76.

FALCONER, D. S. 1967. The inheritance of liability to diseases with variable age of onset, with particular reference to diabetes mellitus. Ann. Hum. Genet., Lond., 31, 1-20.

FARR, J. A. 1977. Male rarity or novelty, female choice behaviour, and sexual selection in the guppy, Poecilia reticulata Peters (Pisces: Poeciliidae). Evolution, 31, 162168.

FISHER, R. A. 1930. The Genetical Theory of Natural Selection. The Clarendon Press, Oxford.

GRANT, B., SNYDER, G. A. AND GLESSNER, S. F. 1974. Frequency-dependent mate selection in Mormoniella vitripennis. Evolution, 28, 259-264.

KARLIN, S. AND RAPER, J. 1979. Sexual selection encounter models. Theor. Pop. Biol., 15, 246-256.

KIRKPATRICK, M. 1982. Sexual selection and the evolution of female choice. Evolution, 36, 1-12.

LANDE, R. 1981. Models of speciation by sexual selection on polygenic traits. Proc. Nat. Acad. Sci., U.S.A., 78, 37213725 .

MAJERUS, M. E. N., O'DONALD, P. AND WEIR, J. $1982 a$. Evidence for preferential mating in Adalia bipunctata. Heredity, 49, 37-49.

MAJERUS, M. E. N., O'DONALD, P. AND WEIR, J. 1982 b. Female mating preference is genetic. Nature, 300, 521-523.

MUGGLETON, J. 1979. Non-random mating in wild populations of polymorphic Adalia bipunctata. Heredity, 42, 57-65.

O'DONALD, P. 1962. The theory of sexual selection. Heredity, $17,541-552$.

O'DONALD, P. 1967. A general model of sexual and natural selection. Heredity, 22, 499-518.

O'DONALD, P. 1978a. Theoretical aspects of sexual selection: a generalized model of mating behaviour. Theor. Pop. Biol., $13,226-243$.

O'DONALD, P. 1978b. A general model of mating behaviour with natural selection and female preference. Heredity, 40 , 427-438.

O'Donald, P. 1980. Genetic Models of Sexual Selection. Cambridge University Press, Cambridge.

O'DONALD, P., AND MAJERUS, M. E. N. 1984. Polymorphism of melanic ladybirds maintained by frequency-dependent sexual selection. Biol. J. Linn. Soc., 23, 101-111.

O'DONALD, P., AND MUGGleton, J. 1979. Melanic polymorphism in ladybirds maintained by sexual selection. Heredity, 43, 143-148.

SEMLER, D. E. 1971. Some aspects of adaptation in a polymorphism for breeding colours in the Threespine Stickleback (Gasterosteas aculeatus). J. Zool. Lond., 165, 291-302.

SPIESS, E. B. 1968. Low frequency advantage in mating of Drosophila pseudoobscura karyotypes. Amer. Natur., 102, 363-379.

SPIESS, L. D. AND SPIESS, E. B. 1969. Minority advantage in interpopulational matings of Drosophila persimilis. Amer. Natur., 103, 155-172.

SPIESS, E. B. AND EHRMAN, L. 1978. Rare male mating advantage. Nature, 272, 188-189.

\section{APPENDIX}

\section{Calculation of variances of estimates of heritabilities}

\section{(i) Definitions}

$\gamma, \gamma^{\prime}$ levels of preference in parental and offspring generations (estimates $\hat{\gamma}, \hat{\gamma}^{\prime}$ )

$v \quad$ frequency of melanics in mating test.

$x, x^{\prime}$ thresholds at which $\gamma, \gamma^{\prime}$ females mate preferentially.

$z$ value of standard normal density, $z=$ $\exp \left(-x^{2}\right) / \sqrt{2 \pi}$

$i$ mean deviate of preferring females, $i=$ $z / \gamma$

$j \quad$ mean deviate of non-preferring females, $j=z /(1-\gamma)$, where $z$ corresponds to $x$ at which $1-\gamma$ females mate randomly.

$\mathrm{S} \quad$ selection differential.

$b$ regression of female offspring on female

parent, $b=\left(x-x^{\prime}\right) / \mathrm{S}$.

$h^{2} \quad$ heritability of preference, $h^{2}=2 b$.

$\mathrm{n}, \mathrm{n}^{\prime} \quad$ sample sizes of mating males in parental and offspring generations.

\section{(ii) Falconer's model}

\section{High Line}

In the high line, $\gamma$ is increased by selection in successive generations. Thus $\gamma^{\prime}>\gamma$, and hence $x>$ $x^{\prime}$, where $x^{\prime}$ and $x$ are the thresholds corresponding to $\gamma^{\prime}$ and $\gamma$. We have shown that

$$
\begin{aligned}
\mathrm{S} & =\gamma i(1-v) /(\gamma+v-\gamma v) \\
h^{2} & =2 b=2\left(x-x^{\prime}\right) / \mathrm{S}
\end{aligned}
$$

The variance of $h^{2}$ is given by the general expression

$$
\begin{aligned}
\operatorname{var}\left(h^{2}\right)= & \left\{\frac{\partial\left[\left(x-x^{\prime}\right) / \mathrm{S}\right]}{\partial x}\right\}^{2} \operatorname{var}(x) \\
& +\left\{\frac{\partial\left[\left(x-x^{\prime}\right) / \mathrm{S}\right]}{\partial x^{\prime}}\right\}^{2} \operatorname{var}\left(x^{\prime}\right)
\end{aligned}
$$

when evaluated at the parameter values (or approximately, their estimates). We have

$$
\begin{aligned}
& \frac{\partial \gamma}{\partial x}=-z=-i \gamma \\
& \frac{\partial z}{\partial x}=-x z \\
& \frac{\partial i}{\partial x}=\left(-\gamma z x+z^{2}\right) / \gamma^{2}=i(i-x)
\end{aligned}
$$


Therefore

$$
\begin{aligned}
\frac{\partial \mathrm{S}}{\partial x} & =(1-v)\left\{\frac{\gamma}{\gamma+v-\gamma v} \cdot \frac{\partial i}{\partial x}+i \frac{\partial}{\partial x}\left[\frac{\gamma}{\gamma+v-\gamma v}\right]\right\} \\
& =(1-v)\left\{\frac{\gamma i(i-x)}{\gamma+v-\gamma v}-\frac{\gamma v i^{2}}{(\gamma+v-\gamma v)^{2}}\right\}
\end{aligned}
$$

and hence

$$
\begin{aligned}
\frac{\partial\left[\left(x-x^{\prime}\right) / \mathrm{S}\right]}{\partial x} & =\frac{1}{\mathrm{~S}}-\frac{\left(x-x^{\prime}\right)}{\mathrm{S}^{2}} \cdot \frac{\partial \mathrm{S}}{\partial x} \\
\frac{\partial\left(x^{\prime} / \mathrm{S}\right)}{\partial x^{\prime}} & =\frac{1}{\mathrm{~S}}
\end{aligned}
$$

Since, as we have shown

$$
\operatorname{var}(\hat{\gamma})=\frac{(1-\gamma)(\gamma+v-\gamma v)}{n(1-v)}
$$

therefore

$$
\begin{aligned}
\operatorname{var}(x) & =\left(1 / \frac{\partial \gamma}{\partial x}\right)^{2} \operatorname{var}(\hat{\gamma}) \\
& =\frac{(1-\gamma)(\gamma+v-\gamma v)}{n \gamma^{2} i^{2}(1-v)}
\end{aligned}
$$

Also,

$$
\operatorname{var}\left(x^{\prime}\right)=\frac{\left(1-\gamma^{\prime}\right)\left(\gamma^{\prime}+v-\gamma^{\prime} v\right)}{\mathrm{n}^{\prime} \gamma^{\prime 2} i^{\prime 2}(1-v)}
$$

Therefore

$$
\begin{aligned}
\operatorname{var}(b)= & {\left[\frac{1}{S}-\frac{\left(x-x^{\prime}\right)}{S^{2}} \cdot \frac{\partial S}{\partial x}\right]^{2} \cdot \operatorname{var}(x) } \\
& +\frac{1}{S^{2}} \cdot \operatorname{var}\left(x^{\prime}\right)
\end{aligned}
$$

and

$$
\operatorname{var}\left(h^{2}\right)=4 \operatorname{var}(b)
$$

\section{Low Line}

The variances of $h^{2}$ for the low line are exactly the same as those derived by Falconer (1965) for his Method 1. In this case, however, $x$ and $x^{\prime}$ are the thresholds corresponding to $1-\gamma$ and $1-\gamma^{\prime}$. Then

$$
\begin{aligned}
j & =z /(1-\gamma) \\
h^{2} & =2 b=2\left(x-x^{\prime}\right) / j \\
\operatorname{var}(x) & =\frac{(1-\gamma)(\gamma+v-\gamma v)}{n j^{2}(1-\gamma)^{2}(1-v)}
\end{aligned}
$$

$$
=\frac{\gamma+v-\gamma v}{n j^{2}(1-\gamma)(1-v)}
$$$$
\operatorname{var}\left(x^{\prime}\right)=\frac{\gamma^{\prime}+v-\gamma^{\prime} v}{n^{\prime} j^{\prime 2}\left(1-\gamma^{\prime}\right)(1-v)}
$$$$
\operatorname{var}(b)=\left[\frac{1}{j}-\frac{\left(x-x^{\prime}\right)(j-x)}{j}\right]^{2} \operatorname{var}(x)+\frac{1}{j^{2}} \operatorname{var}\left(x^{\prime}\right)
$$

$\operatorname{var}\left(h^{2}\right)=4 \operatorname{var}(b)$

\section{(iii) Bulmer's model}

\section{High Line}

In Bulmer's model

$$
h^{2}=\frac{2\left(\gamma^{\prime}-\gamma\right)(\gamma+v-\gamma v)}{\gamma(1-\gamma)(1-v)}
$$

Therefore

$$
\operatorname{var}\left(h^{2}\right)=\left(\frac{\gamma h^{2}}{\partial \gamma}\right)^{2} \operatorname{var}(\hat{\gamma})+\left(\frac{\gamma h^{2}}{\partial \gamma^{\prime}}\right)^{2} \operatorname{var}\left(\hat{\gamma}^{\prime}\right)
$$

where

$$
\begin{aligned}
\frac{\partial h^{2}}{\partial \gamma}= & 2\left[\gamma(1-\gamma)\left(\gamma^{\prime}-\gamma^{\prime} v-2 \gamma-v+2 \gamma v\right)-\left(\gamma^{\prime}-\gamma\right)\right. \\
& \times(1-2 \gamma)(\gamma+v-\gamma v)] /\left[\gamma^{2}(1-\gamma)^{2}(1-v)\right] \\
\frac{\partial h^{2}}{\partial \gamma^{\prime}}= & \frac{2(\gamma+v-\gamma v)}{(1-\gamma)(1-v)}
\end{aligned}
$$

$$
\begin{aligned}
& \operatorname{var}(\hat{\gamma})=\frac{(1-\gamma)(\gamma+v-\gamma v)}{n(1-v)} \\
& \operatorname{var}\left(\hat{\gamma}^{\prime}\right)=\frac{\left(1-\gamma^{\prime}\right)\left(\gamma^{\prime}+v-\gamma^{\prime} v\right)}{n^{\prime}(1-v)}
\end{aligned}
$$

The Low Line

$$
\begin{aligned}
h^{2} & =\frac{2\left(\gamma-\gamma^{\prime}\right)(1-v)}{\gamma+v-\gamma v} \\
\operatorname{var}\left(h^{2}\right) & =\left(\frac{\partial h^{2}}{\partial \gamma}\right)^{2} \operatorname{var}(\hat{\gamma})+\left(\frac{\partial h^{2}}{\partial \gamma^{\prime}}\right)^{2} \operatorname{var}\left(\hat{\gamma}^{\prime}\right)
\end{aligned}
$$

where

$$
\begin{aligned}
& \frac{\gamma h^{2}}{\partial \gamma}=\frac{2\left[(1-v)(\gamma+v-\gamma v)-\left(\gamma-\gamma^{\prime}\right)(1-v)^{2}\right]}{(\gamma+v-\gamma v)^{2}} \\
& \frac{\partial h^{2}}{\partial \gamma^{\prime}}=-\frac{2(1-v)}{\gamma+v-\gamma v}
\end{aligned}
$$

